\title{
CRESCIMENTO INICIAL DE DUAS CULTIVARES DE CAFEEIRO ADENSADO INFLUENCIADO POR NÍVEIS DE IRRIGAÇÃO LOCALIZADA ${ }^{1}$
}

\author{
MÁRCIO S. SANTANA ${ }^{2}$, CARLOS A. DA S. OLIVEIRA ${ }^{3}$, MICHAEL QUADROS ${ }^{4}$
}

\begin{abstract}
RESUMO: O experimento foi conduzido na Fazenda Água Limpa, Universidade de Brasília, tendo como objetivo avaliar o crescimento das cultivares de café IAPAR-59 e Obatã, submetidas a cinco níveis de irrigação por gotejamento durante o primeiro ano de formação e estudar formas de manejo da água do solo. $\mathrm{O}$ delineamento experimental usado foi o de blocos completos ao acaso para o fator irrigação em parcelas, com o fator cultivar em subparcela e o fator tempo em dias após o transplante (dat) em subsubparcela, com seis repetições. Os cinco níveis de irrigação foram tensões de 20; 40 e $60 \mathrm{kPa}$ determinadas com o auxílio de tensiômetros, sistema Irrigas com tensão definida pelo próprio sensor e sem irrigação. As variáveis de crescimento avaliadas foram índice de área foliar, número de folhas, diâmetro do caule, altura de plantas e número de ramos plagiotrópicos. Aos 316 dat, os tratamentos irrigados tiveram o mesmo comportamento de crescimento, mas foram significativamente maiores em relação ao tratamento não irrigado. O sistema Irrigas mostrou ser uma opção para o manejo adequado da água com manutenção nula. As cultivares IAPAR-59 e Obatã têm comportamento de crescimento diferenciado, com todas as variáveis avaliadas favorecendo esta última.
\end{abstract}

PALAVRAS-CHAVE: coffea arabica, manejo de água do solo, sistema Irrigas.

\section{INITIAL GROWTH OF TWO HIGH-DENSITY COFFEE TREE CULTIVARS INFLUENCED BY DRIP IRRIGATION LEVELS}

SUMMARY: The experiment was carried out at "Água Limpa" Farm, University of Brasilia. The objective was to evaluate growth of IAPAR-59 and Obatã cultivars using five drip irrigation levels, during the crop of the first year and to study soil water management. It was used a randomized complete block design for the irrigation factor, with the cultivar factor as a split plot on irrigation and the factor time in days after transplanting (dat) as a split plot on cultivar. The five irrigation levels were 20; 40 and $60 \mathrm{kPa}$, established using tensiometers; Irrigas system with soil water tension defined by its sensor; and no irrigation. Growth variables evaluated were leaf area index, leaf number, steam diameter, plant height and plagiotropic branches number. At 316 dat irrigated treatments had similar type of growth but they were significantly higher than the non-irrigated one. Irrigas system has proved to be an option for an adequate water management with null maintenance. IAPAR-59 and Obatã cultivars had significant differences with all growth variable evaluated favoring the last one.

KEYWORDS: coffea arabica, soil water management, Irrigas system.

\footnotetext{
${ }^{1}$ Extraído da dissertação de mestrado do primeiro autor apresentada à Faculdade de Agronomia e Medicina Veterinária, UnB.

${ }^{2}$ Eng ํ Agrônomo, Pós-Graduando na área de concentração Gestão Solo e Água, FAV, UnB, e-mail: santanams@ unb.br

${ }^{3}$ Prof. Titular, FAV, UnB, Caixa Postal 04508, Brasília - DF, e-mail: dasilvao@unb.br

${ }^{4}$ Eng ${ }^{\mathrm{o}}$ Agrônomo, FAV, UnB, Brasília - DF.

Recebido pelo Conselho Editorial em: 6-10-2003

Aprovado pelo Conselho Editorial em: 4-10-2004
} 


\section{INTRODUÇÃO}

A irrigação do cafeeiro tem ganhado importância, principalmente, em áreas com estação seca bem definida, como é o caso do Cerrado Brasileiro (NAZARENO, 2002). No Distrito Federal, onde ocorre insuficiente disponibilidade hídrica, a cultura do cafeeiro requer o uso da irrigação para diminuir ou eliminar as deficiências hídricas observadas nas suas fases críticas (SILVA et al., 2000).

Estudando o efeito das densidades de plantio de $7.143 ; 1.429$ e 893 plantas ha ${ }^{-1}$, PAVAN \& CHAVES (1996) destacaram que o aumento na densidade populacional de cafeeiros aumenta o teor de água no solo nas profundidades de 0 a 20 e 20 a $40 \mathrm{~cm}$, dentro das linhas de plantas, por reduzir a evaporação por meio do maior sombreamento. Por outro lado, densidades de plantio maiores proporcionam maior densidade de raízes num mesmo volume de solo e aumentam a transpiração, o que, certamente, tem implicações sobre o manejo da água do cafeeiro.

A irrigação do cafeeiro tem sido realizada preferencialmente com uso de sistemas pressurizados por aspersão ou localizada (SOARES et al., 2001). Porém, em sistemas de irrigação localizada, ocorre economia de água, uma vez que se molha apenas a região próxima à planta e se obtém maior eficiência de aplicação. Favorece, ainda, a irrigação localizada o fato de, no primeiro ano de cultivo do cafeeiro, predominar a evaporação da água do solo sobre a transpiração da cultura.

O monitoramento da água do solo pode ser feito usando tensiômetros, mas requerem manutenção adequada e freqüiente dos mesmos. Recentemente, foi desenvolvido o sistema Irrigas (CALBO, 2000), que possibilita o monitoramento da água do solo, sendo necessários estudos de validação desse equipamento sobre condições contínuas de campo. COELHO et al. (1995) afirmaram que o local de monitoramento do estado da água no solo, para gotejador instalado na superfície do solo, corresponde às profundidades de $0,1 \mathrm{a}$ 0,4 $\mathrm{m}$, e distâncias radiais do gotejador maiores que $0,1 \mathrm{~m}$. Essa localização dos sensores de tensão, pontos de emissores e planta é de extrema importância para o adequado manejo da água de irrigação, como relataram COELHO \& OR (1999).

O cafeeiro requer grande quantidade de mão-de-obra na colheita manual, sendo, por isso, desejável o plantio no mesmo local de cultivares de maturação precoce e de maturação tardia de frutos. As cultivares IAPAR-59, de maturação medianamente precoce de frutos (SERA et al., 2002), e Obatã, de maturação média a tardia de frutos (FAZUOLI, 1999), são consideradas de porte baixo, indicadas para o plantio adensado e, quando plantadas num mesmo local, podem melhorar o escalonamento das atividades de colheita e pós-colheita. Entretanto, para o adequado manejo da irrigação, é necessário quantificar se as necessidades hídricas dessas cultivares são semelhantes.

Este trabalho teve o objetivo de indicar formas de manejo da água de irrigação por gotejamento para as cultivares de cafeeiro IAPAR-59 e Obatã (Coffea arabica L.), durante o primeiro ano de plantio adensado, estudando o crescimento dessas cultivares com e sem irrigação.

\section{MATERIAL E MÉTODOS}

A pesquisa foi conduzida na Fazenda Água Limpa, UnB - DF, latitude $15^{\circ} 56^{\prime} \mathrm{S}$, longitude $47^{\circ} 56^{\prime} \mathrm{W}$ e altitude média de $1.080 \mathrm{~m}$. Segundo Köeppen, o clima é do tipo Aw tropical chuvoso de inverno seco. O solo é classificado como Latossolo Vermelho-Amarelo - LVA, textura argilosa, fase Cerrado. A equação da curva de retenção de água no solo foi $\theta \mathrm{v}=43,6263-2,9076 \ln \mathrm{x}\left(\mathrm{r}^{2}=0,91\right)$, sendo $\theta \mathrm{v}$ o teor volumétrico de água do solo $(\%)$ e x a tensão de água $(\mathrm{kPa})$.

Procederam-se às adubações de plantio e cobertura seguindo recomendações para o uso de corretivos e fertilizantes em Minas Gerais, quinta aproximação.

O transplante das cultivares IAPAR-59 e Obatã, ambas aos nove meses de idade (março-2002), foi feito com as mudas apresentando área foliar de 243,4 e $300,8 \mathrm{~cm}^{2}$; número de 11,6 e 10,5 folhas; 
diâmetro do caule de 0,40 e $0,38 \mathrm{~cm}$; altura de planta de 18,7 e $30,3 \mathrm{~cm}$, respectivamente. $\mathrm{O}$ espaçamento entre plantas foi de $2,0 \times 0,5 \mathrm{~m}$ em linhas duplas espaçadas $3,6 \mathrm{~m}$, com 7.142 plantas $\mathrm{ha}^{-1}$.

O delineamento experimental foi o de blocos completos ao acaso para o fator irrigação, com o fator cultivar em subparcela, o fator tempo em subsubparcela, com cinco tratamentos e seis repetições. A área total da parcela foi de $123,2 \mathrm{~m}^{2}$ e a área útil da subparcela foi de $5,6 \mathrm{~m}^{2}$. Os dados de crescimento foram coletados em quatro plantas centrais dessa área útil.

Os tratamentos foram: com irrigação em tensão de $20 \mathrm{kPa}$; com irrigação em tensão de $40 \mathrm{kPa}$; com irrigação em tensão de $60 \mathrm{kPa}$; com irrigação pelo sistema Irrigas, e sem irrigação.

O sistema de irrigação por gotejamento foi instalado no plantio, em março de 2002. Os tratamentos de irrigação foram impostos a partir de 5 de junho (76 dat). As linhas laterais apresentaram emissores espaçados em $0,40 \mathrm{~m}$ e com vazão média de $2,0 \mathrm{~L} \mathrm{~h}^{-1}$, na pressão de $10 \mathrm{mca}$. $\mathrm{O}$ monitoramento da água do solo foi feito com tensiômetros instalados a $20 \mathrm{e} 40 \mathrm{~cm}$ de profundidade e acerca de $10 \mathrm{~cm}$ ao lado da planta, procurando-se manter eqüidistância entre o emissor e o tensiômetro. $\mathrm{O}$ tensiômetro, à profundidade de $20 \mathrm{~cm}$, foi usado para o controle da irrigação. Com o sensor Irrigas, o monitoramento da água também foi feito a essa profundidade.

Nas parcelas do tratamento sem irrigação, o monitoramento do teor de água do solo, em volume, foi feito usando a reflectometria de domínio do tempo. A curva de calibração do equipamento, com $\mathrm{R}^{2}=0,989$, foi do tipo $\mathrm{X}=[\mathrm{y}-\mathrm{a} / \mathrm{b}]^{1 / \mathrm{C}}$, sendo $\mathrm{X}$ o teor de água do solo corrigido, em porcentagem; $\mathrm{y}$ o teor de água do solo, em porcentagem, obtido pelo aparelho; $\mathrm{a}=70,2088 ; \mathrm{b}=35,6467$, e c $=0,0887$.

Para determinar a área foliar, foi estabelecida relação entre área e comprimento, medido desde o ponto de inserção do limbo no pecíolo até o seu ápice. A área de cada folha foi estimada segundo CALDAS et al. (1992). Com os dados de comprimento (x), em cm, e área de cada folha (y), em $\mathrm{cm}^{2}$, ajustaram-se as equações: $\mathrm{y}_{1}=0,3003 \mathrm{x}^{2}-0,0854 \mathrm{x}, \operatorname{com} \mathrm{R}^{2}=0,98$ e para $1 \leq \mathrm{x} \leq 16 \mathrm{~cm}$, utilizada até a quarta avaliação; e $y_{2}=0,3052 \mathrm{x}^{2}-0,0342 \mathrm{x}$, com $\mathrm{R}^{2}=0,982$ e para $1 \leq \mathrm{x} \leq 22 \mathrm{~cm}$, utilizada na quinta e sexta avaliações. Assim, medindo-se todas as folhas de uma planta, foi possível obter os valores do índice de área foliar por planta.

O diâmetro do caule foi determinado a $0,05 \mathrm{~m}$ de altura, em relação à superfície do solo, com paquímetro. A altura da planta foi determinada da superfície do solo ao meristema apical. Os ramos plagiotrópicos e as folhas do cafeeiro foram quantificados a partir de $1 \mathrm{~cm}$ de comprimento. Essas avaliações foram feitas de 45 em 45 dias, de 20 de junho de 2002 a 5 de fevereiro de 2003.

Os dados diários de temperatura e umidade relativa do ar, precipitação e evaporação do tanque Classe A foram coletados em uma estação meteorológica localizada próxima da área experimental.

\section{RESULTADOS E DISCUSSÃO}

Em relação aos dados climáticos do período de março de 2002 a março de 2003, observou-se que as temperaturas médias mensais (Figura 1A) apresentaram maior amplitude térmica no mês de agosto. Entretanto, a menor temperatura mínima média mensal ocorreu no mês de junho $\left(9,6{ }^{\circ} \mathrm{C}\right)$ e a maior temperatura máxima média mensal em outubro $\left(31,6^{\circ} \mathrm{C}\right)$, portanto, fora da faixa de temperatura ótima de 18 a $23^{\circ} \mathrm{C}$ sugerida por MIRANDA et al. (1999). As temperaturas absolutas médias mensais ficaram na faixa ótima (Figura 1A). A maior amplitude da umidade relativa média mensal ocorreu em setembro, quando se verificaram maiores demandas de evaporação média mensal (Figura 1B e 1C). A precipitação foi praticamente nula de maio a agosto, com a evaporação acumulada pelo tanque "Classe A" superando-a durante o período (Figura 1D). Dessa forma, foi possível estabelecer os diversos tratamentos de irrigação, principalmente no período seco e de maior demanda evaporativa. 

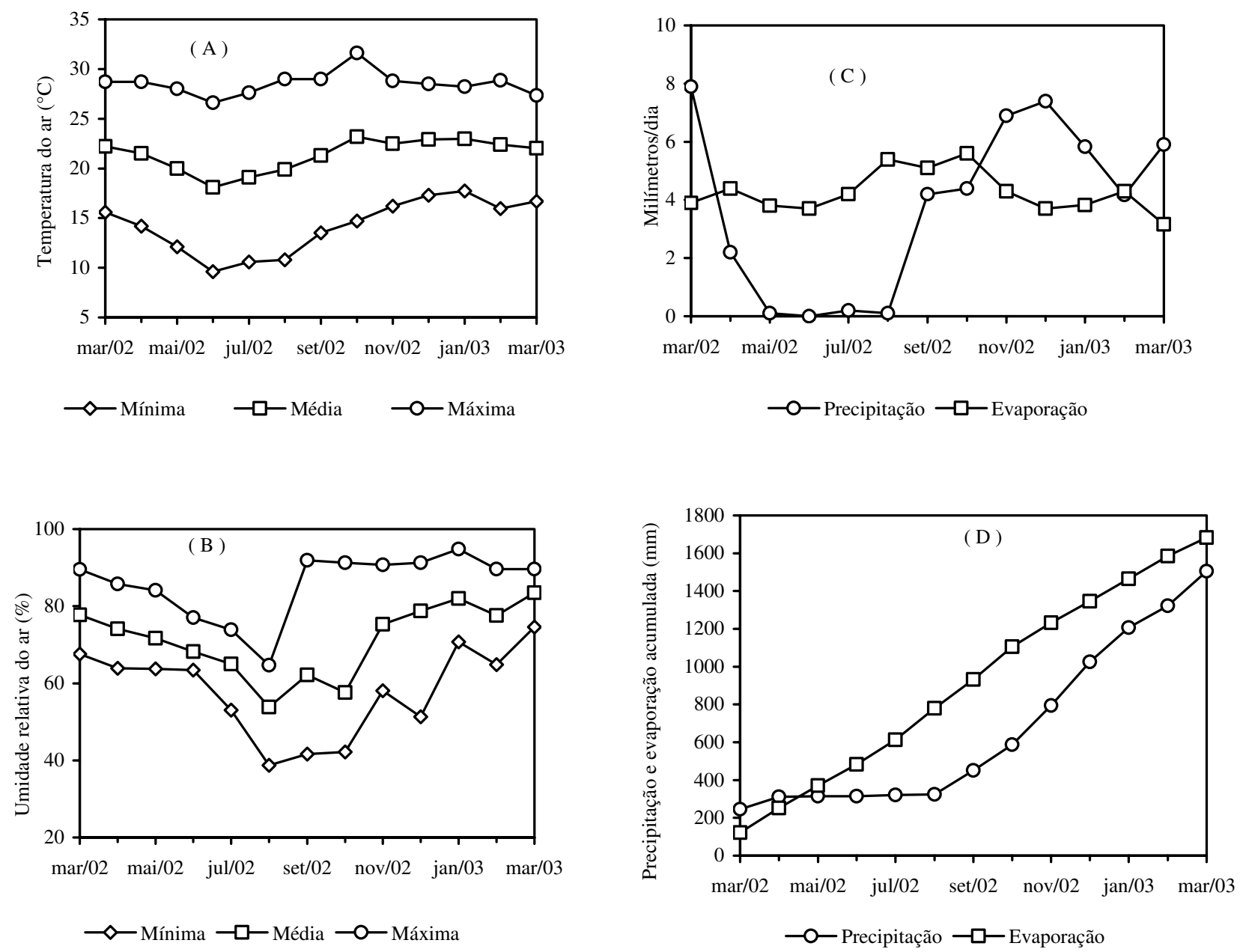

FIGURA 1. Dados climáticos médios mensais observados no primeiro ano após o transplante das mudas de cafeeiro: (A) temperatura; (B) umidade relativa; (C) precipitação e evaporação do tanque "Classe A"; (D) precipitação e evaporação acumuladas.

As tensões médias de água no solo, relativas aos diversos tratamentos (Figura 2A), possibilitaram observar que, na tensão de $20 \mathrm{kPa}$, houve menor variação tanto na época seca como na chuvosa. A tensão de $60 \mathrm{kPa}$ proporcionou as maiores variações na tensão de água no solo no período chuvoso. As tensões obtidas nos tratamentos de $40 \mathrm{kPa}$ e Irrigas oscilaram para baixo em função das chuvas, podendo-se afirmar que o tratamento com o sistema Irrigas consumiu uma lâmina de água pouco maior do que o tratamento de $40 \mathrm{kPa}$ (Figura 2B). Mesmo no período chuvoso, houve a necessidade de irrigação no tratamento de $20 \mathrm{kPa}$. No tratamento não irrigado, nos períodos frio e seco, foi observado que o teor de água no solo chegou a atingir $22,4 \%$, correspondente a $1.500 \mathrm{kPa}$, evidenciando que ambas as cultivares, apesar de submetidas a déficit hídrico elevado, toleram tal estresse. 

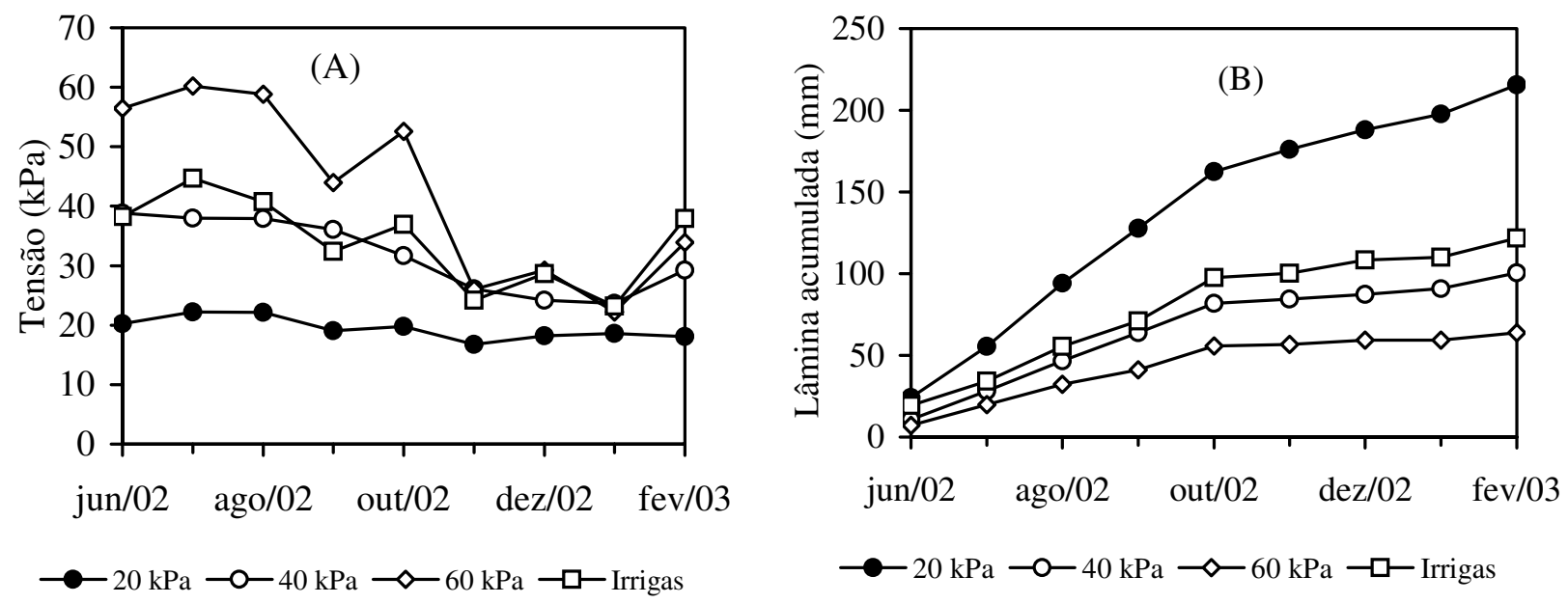

FIGURA 2. Valores médios de: (A) tensões de água no solo e (B) lâmina acumulada de água da irrigação, em milímetros, observados de 91 a 316 dias após o transplante do cafeeiro.

Nos meses de junho, julho e agosto (inverno seco), o consumo médio de água, em função da área molhada (22\% da área plantada), foi: 0,$8 ; 1,01$ e $1,25 \mathrm{~mm} \mathrm{dia}^{-1}$ para os tratamentos de $20 \mathrm{kPa} ; 0,36$; 0,56 e $0,60 \mathrm{~mm} \mathrm{dia}^{-1}$ para os tratamentos de $40 \mathrm{kPa} ; 0,24 ; 0,41$ e $0,40 \mathrm{~mm}$ dia $^{-1}$ para os tratamentos de $60 \mathrm{kPa}$; e 0,64; 0,48 e 0,68 mm dia ${ }^{-1}$ para o sistema Irrigas, respectivamente. Esses valores são coerentes, em ordem de magnitude, aos encontrados por ANTUNES (2000), em meses de menores ou de quase nenhuma precipitação (abril a agosto) com valores da ETc variando de 1,03; 0,90;0,95 e $1,07 \mathrm{~mm} \mathrm{dia}^{-1}$ para a cultivar "Catuaí vermelho IAC-99", e 1,09; 0,95; 1,01 e 1,20 mm dia para a $^{-1}$ cultivar "Acaiá Cerrado seleção MG-1454” sob diferentes manejos de água utilizada, entre 390 e 600 dat.

Para todas as variáveis de crescimento avaliadas, houve diferenças altamente significativas entre regimes hídricos, cultivares, épocas e entre as interações regime hídrico versus época e cultivar versus época. Os tratamentos irrigados não diferiram entre si, mas diferiram do tratamento não irrigado. Não houve tríplice interação entre regime hídrico, cultivar e época, indicando que as duas cultivares apresentaram a mesma resposta aos tratamentos de irrigação nesse período.

\section{Índice de área foliar (IAF)}

Para os tratamentos irrigados, o IAF apresentou diferença significativa a partir de 226 dat (Figura 3A) e para o sem irrigação, só a partir de 271 dat. Mesmo com a irrigação, o cafeeiro teve baixo crescimento durante a estação fria e seca, evidenciando que o efeito da temperatura do ar é mais relevante do que o regime hídrico para a redução do IAF. Entretanto, a manutenção do crescimento vegetativo reduzido nos tratamentos irrigados sugere a importância da irrigação nesse período, o que também está de acordo com ANTUNES (2000).

O conhecimento da área foliar da planta permite uma estimativa da perda de água, pois as folhas são responsáveis pela troca gasosa com o ambiente e afetam a definição de estratégias de manejo da irrigação (FAVARIN et al., 2002). Isso nos permite afirmar que, nos tratamentos irrigados, houve maior troca gasosa com o ambiente em relação ao tratamento não irrigado.

$\mathrm{Na}$ interação entre as cultivares IAPAR-59 e Obatã versus épocas de avaliação (Figura 3B), houve crescimento diferenciado a partir de 226 dat em diante, já em plena estação chuvosa, chegando a atingir o valor médio final de 0,737 e $0,936 \mathrm{~m}^{2} \mathrm{~m}^{-2}\left(1,31 \mathrm{~m}^{2}\right.$ de área foliar por planta), respectivamente. Em plantas da cultivar Mundo Novo IAC 388-17 enxertada em cultivar Apoatã IAC 2258, FAVARIN et al. (2002) estimaram IAF, aos 450 e 510 dat, iguais a 0,27 e $0,58 \mathrm{~m}^{2} \mathrm{~m}^{-2}\left(0,67\right.$ e $1,45 \mathrm{~m}^{2}$ de área foliar por planta), respectivamente, valores esses abaixo do encontrado nesta pesquisa. Por sua vez, 
NAZARENO (2002), utilizando equipamento eletrônico para determinação da área foliar, demonstrou que aos 383 dat as plantas irrigadas atingiram o IAF de $1,16 \mathrm{~m}^{2} \mathrm{~m}^{-2}\left(1,62 \mathrm{~m}^{2}\right.$ de área foliar por planta) e para o cafeeiro não irrigado, $0,66 \mathrm{~m}^{2} \mathrm{~m}^{-2}\left(0,92 \mathrm{~m}^{2}\right.$ de área foliar por planta), valores esses próximos aos obtidos nesta pesquisa. Esses resultados sugerem um comportamento específico para cada cultivar ou mesmo combinação de enxerto e porta-enxerto utilizada e práticas culturais.
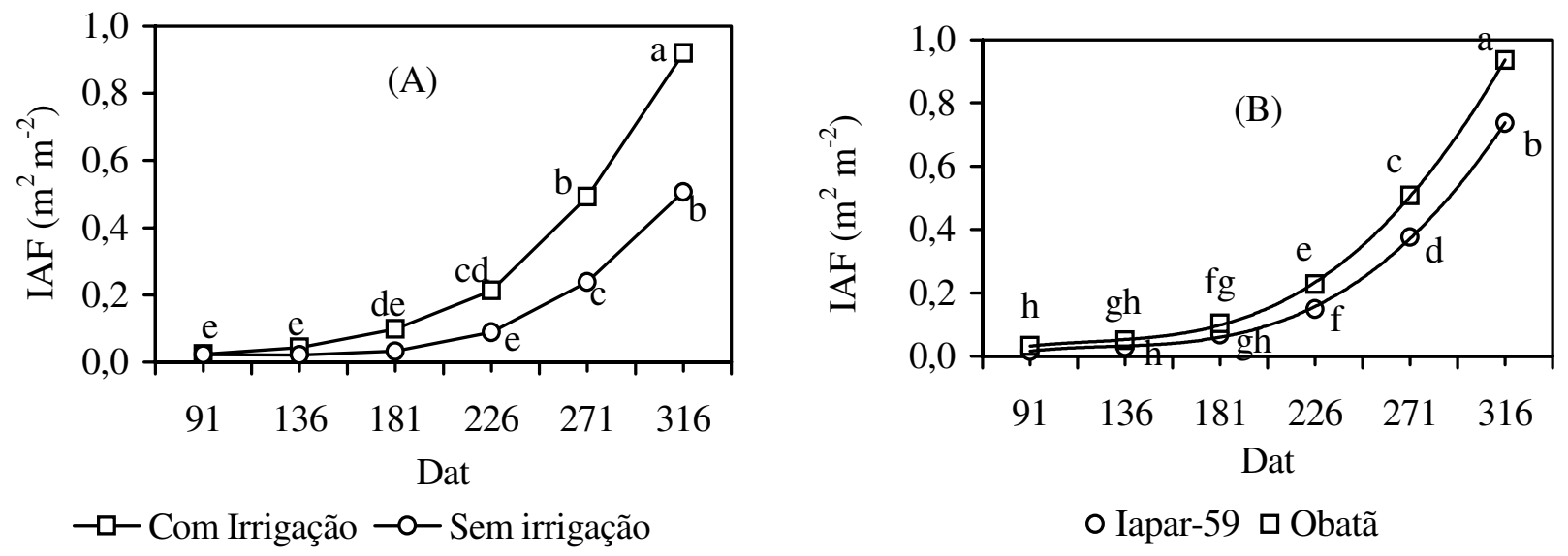

FIGURA 3. Índice de área foliar em função do regime hídrico, da cultivar de cafeeiro e da época de avaliação. Médias seguidas da mesma letra não diferem entre si, pelo teste de Tukey, a 5\% de probabilidade.

\section{Número de folhas}

Nos tratamentos irrigados e não irrigados, somente houve diferença significativa a partir de 226 dat (Figura 4A), ou seja, no início da estação chuvosa, à semelhança do comportamento observado para IAF, sugerindo que as plantas estão emitindo folhas em resposta às chuvas e às temperaturas mais elevadas, iniciadas em setembro. A diferença no número de folhas entre as duas cultivares surgiu a partir de 181 dat (Figura 4B), com superioridade da cultivar Obatã.

O número final de folhas aos 316 dat foi 336 para Obatã e 275 para IAPAR-59, estando acima e abaixo, respectivamente, do valor 321 folhas relatadas por FAVARIN et al. (2002) em cafeeiro Mundo Novo sobre Apoatã, aos 450 dat. Tal comportamento evidencia a necessidade de estudos específicos para os diversos genótipos da espécie Coffea arabica L. e práticas culturais.
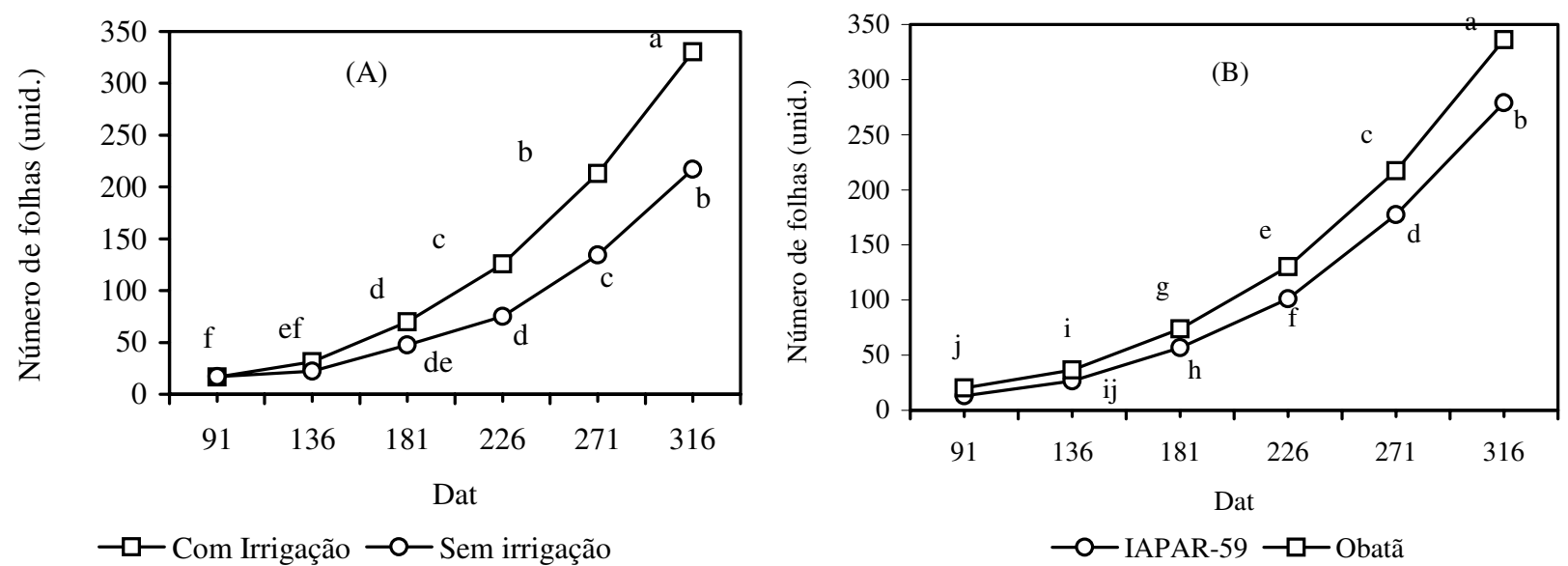

FIGURA 4. Número de folhas em função do regime hídrico, da cultivar de cafeeiro e da época de avaliação. Médias seguidas da mesma letra não diferem entre si, pelo teste de Tukey, a $5 \%$ de probabilidade. 


\section{Diâmetro do caule}

Nos tratamentos com irrigação, houve diferença significativa a partir de 181 dat, com $0,77 \mathrm{~cm}$ de diâmetro do caule. Sem irrigação, observou-se diferença significativa a partir dos 226 dat, com diâmetro de caule de 0,69 cm (Figura 5A), sendo os dados semelhantes aos encontrados por SCALCO et al. (2002).

Dentro das cultivares IAPAR-59 $(0,45 \mathrm{~cm})$ e Obatã $(0,55 \mathrm{~cm})$, observou-se crescimento diferenciado já a partir da primeira avaliação aos 91 dat (Figura 5B). Considerando que ambas apresentaram o mesmo valor de $0,4 \mathrm{~cm}$ por ocasião do plantio e que os tratamentos irrigados só foram praticados a partir de 76 dat, constata-se a maior taxa de crescimento em diâmetro do caule da Obatã.

Quanto à taxa de crescimento da cultivar IAPAR-59, só houve diferença significativa a partir de 181 dat, confirmando as menores taxas de crescimento dessa cultivar em relação a Obatã.
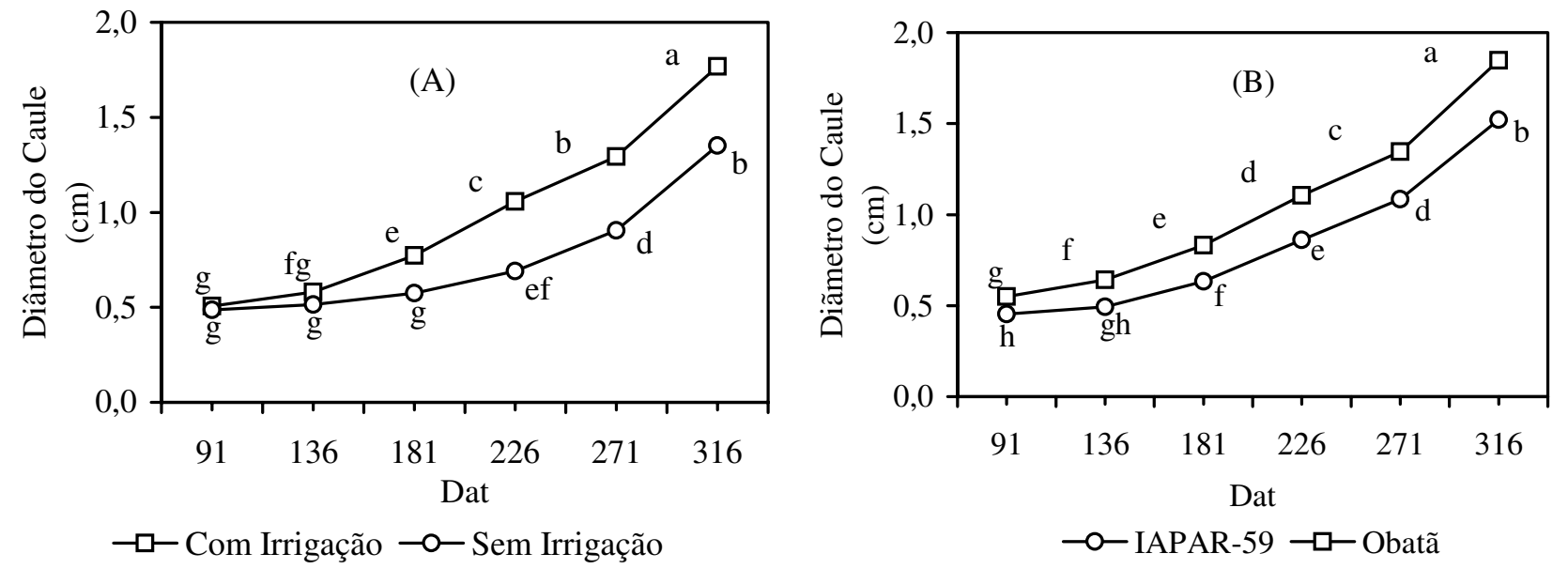

FIGURA 5. Diâmetro do caule em função do regime hídrico, da cultivar de cafeeiro e da época de avaliação. Médias seguidas da mesma letra não diferem entre si, pelo teste de Tukey, a $5 \%$ de probabilidade.

\section{Altura de planta}

Entre os tratamentos irrigados e não irrigados, esse crescimento foi significativo a partir de 181 dat (Figura 6A), no final da estação seca, evidenciando o efeito favorável da irrigação sobre essa variável.

As cultivares IAPAR-59 $(19,9 \mathrm{~cm})$ e Obatã $(28,8 \mathrm{~cm})$ apresentaram alturas diferentes, da primeira avaliação em diante (Figura 6B), mas apresentaram similares taxas médias anuais de crescimento, já que a diferença de $11,7 \mathrm{~cm}$ observada entre as cultivares, por ocasião do plantio, foi idêntica $(11,6 \mathrm{~cm})$ àquela observada aos 316 dat. Assim, comparando com as demais variáveis de crescimento analisadas, a altura é a menos afetada em relação às condições iniciais de plantio. 

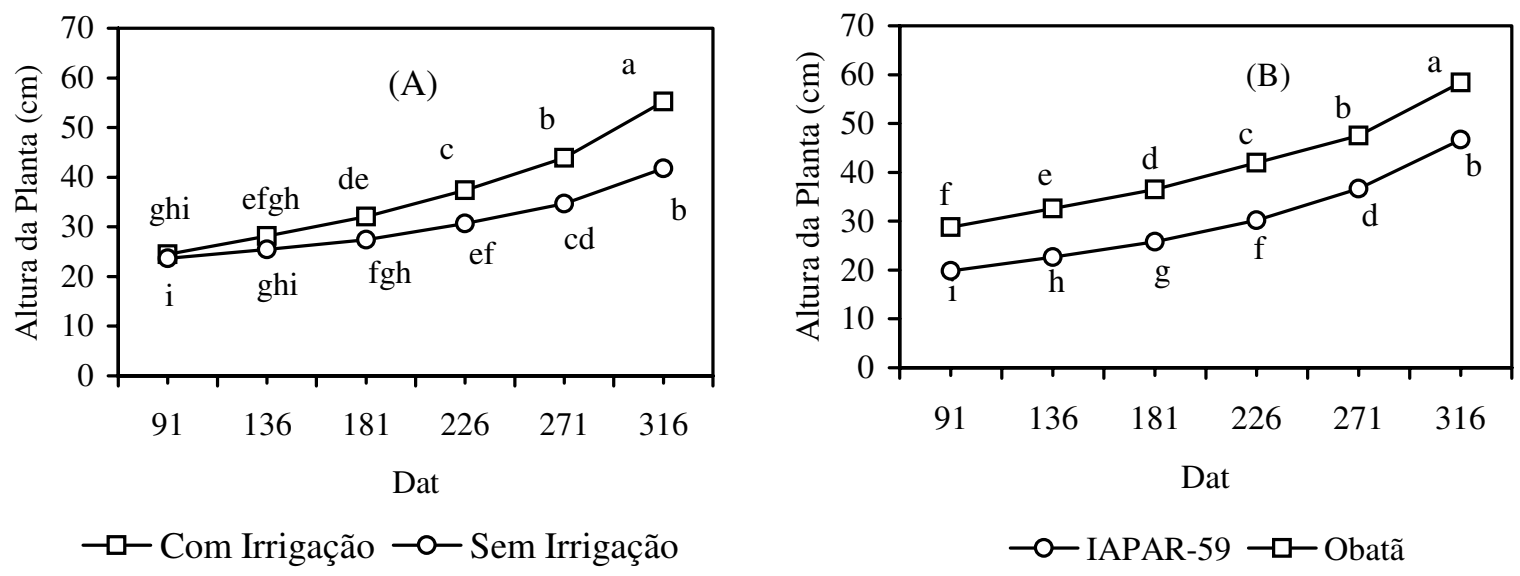

FIGURA 6. Altura de planta em função do regime hídrico, da cultivar de cafeeiro e da época de avaliação. Médias seguidas da mesma letra não diferem entre si, pelo teste de Tukey, a $5 \%$ de probabilidade.

\section{Número de ramos plagiotrópicos}

Diferenças significativas nos tratamentos irrigados $(16,4)$ e não irrigados $(13,1)$ ocorreram a partir de 271 dat em diante, em pleno período chuvoso (Figura 7A). Resultados semelhantes foram obtidos por SILVA (2002) com diferenças observadas aos 223 dat. ANTUNES (2000) observou semelhante efeito do regime hídrico, obtendo, em tratamentos irrigados, 24 ramos de "Catuaí vermelho IAC-99" e 32 ramos de "Acaiá Cerrado", aos 360 dat.

Isoladamente, os tratamentos irrigados e não irrigados mostraram diferenças entre épocas a partir de 181 dat, no início da estação chuvosa, sendo observada maior taxa de crescimento para os tratamentos irrigados. Sendo essa variável correlacionada diretamente com a produção (ANTUNES, 2000), pode-se sugerir que os tratamentos irrigados podem vir a ter melhor produtividade.

Observando as cultivares IAPAR-59 $(10,6)$ e Obatã $(11,9)$, notou-se crescimento significativo aos 226 dat (Figura 7B).
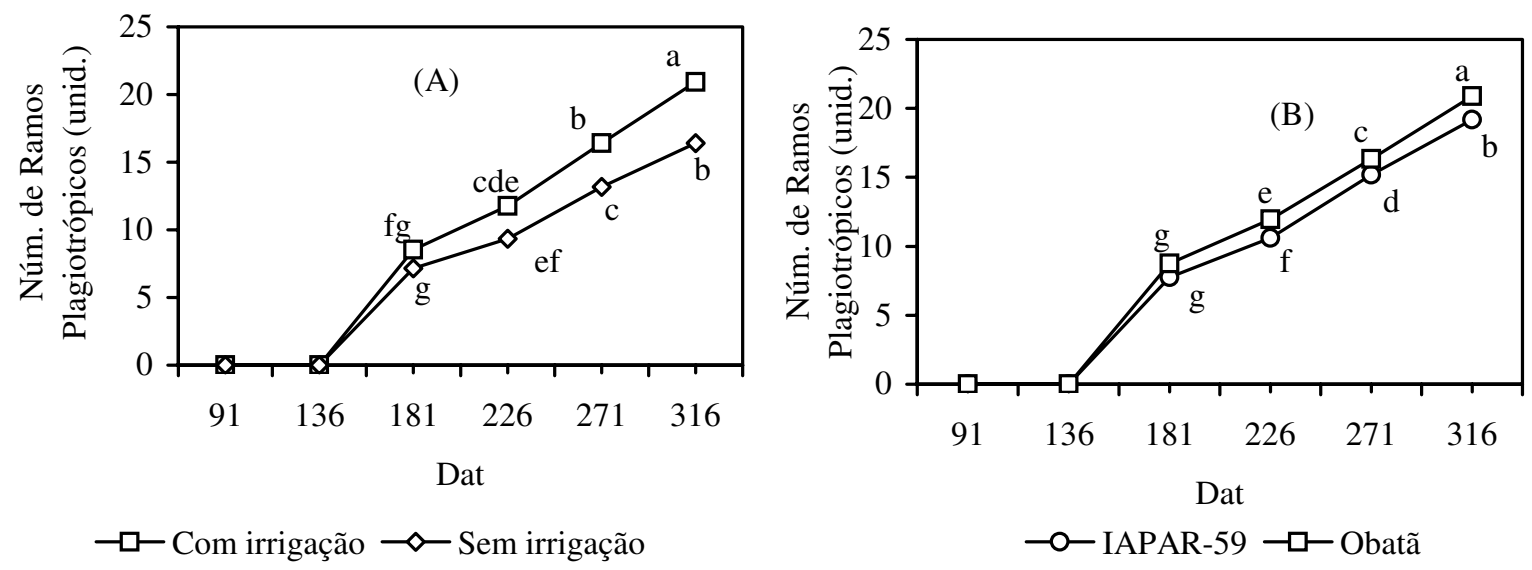

FIGURA 7. Número de ramos plagiotrópicos em função do regime hídrico, da cultivar de cafeeiro e da época de avaliação em dias após o transplante (dat). Médias seguidas da mesma letra não diferem entre si, pelo teste de Tukey, a 5\% de probabilidade. 


\section{Regimes hídricos}

Analisando as médias das variáveis de crescimento em relação aos regimes hídricos aplicados, observa-se não haver diferenças significativas dentro dos tratamentos irrigados, podendo-se optar pelo manejo da irrigação com $60 \mathrm{kPa}$, para maior economia de água e mão-de-obra. Tal resultado difere dos encontrados por MORALES (1981), que observou maiores valores de altura e diâmetro do caule do cafeeiro quando a umidade do solo foi mantida em níveis próximos à capacidade de campo e, também, em desacordo com SCALCO (2002), estudando tensões de 20; 80; 140 e $200 \mathrm{kPa}$, concluindo que a tensão de $20 \mathrm{kPa}$ apresentou os maiores valores de crescimento da cultivar Rubi, aos 300 dat.

O sistema Irrigas funcionou adequadamente durante o período do experimento, sendo mais adequado que o tensiômetro, principalmente, quanto à manutenção do equipamento, que foi nula.

Os tensiômetros apresentaram o inconveniente da reposição freqüente de água destilada e maior vulnerabilidade aos tratos culturais, com quebra do equipamento.

\section{CONCLUSÕES}

Do primeiro ao $316^{\circ}$ dat do cafeeiro, não há diferença no comportamento das cultivares IAPAR59 e Obatã irrigadas em tensões de água no solo de 20; 40 e $60 \mathrm{kPa}$, e com o sistema Irrigas, mas há diferença entre o uso ou não da irrigação, com os tratamentos irrigados impondo maiores valores e taxas de crescimento à planta. O sistema Irrigas não apresentou manutenção no período do experimento e é uma opção para o manejo da irrigação na fase inicial do cafeeiro.

Nos tratamentos não irrigados, a cultivar Obatã apresentou maiores valores do que a IAPAR-59, em todos os parâmetros de crescimento analisados. Entretanto, independentemente do genótipo, este crescimento também é estimulado por fatores meteorológicos, especialmente a temperatura, associada ao teor de água no solo.

\section{AGRADECIMENTOS}

À FAV/FAL/UnB e ao CNPq, pela concessão de auxílio financeiro para o projeto.

\section{REFERÊNCIAS}

ANTUNES, R.C.B. Determinação da evapotranspiração e influência da irrigação e da fertirrigação em componentes vegetativos, reprodutivos e nutricionais do café arábica. 2000. $162 \mathrm{f}$. Dissertação (Mestrado em Manejo de Irrigação) - Universidade Federal de Viçosa, Viçosa - MG, 2000.

CALBO, A.G. Sistema de controle gasoso de irrigação baseado na determinação de umidade do solo por meio de cápsulas porosas. Brasília: Embrapa Hortaliças, 2000. 10 p. (PI 0004264-1)

CALDAS, L.S.; BRAVO, C.; PICCOLO, H.; FARIA, C.R.S.M. Measurement of leaf area with a hand-scanner linked to a microcomputer. Revista Brasileira de Fisiologia Vegetal, Brasília, v.4, n.1, p.17-20, 1992.

COELHO, E.F.; OR, D. Modelo de distribuição de água e de potencial matricial no solo sob gotejamento com extração de água por raízes. Pesquisa Agropecuária Brasileira, Brasília, v.34, n.2, p.225-34, 1999.

COELHO, E.F.; OR, D.; ANDRADE, C. de L.T. de. Avaliação de regime permanente em irrigação por gotejamento e posicionamento de sensores de umidade e de potencial matricial no bulbo molhado. Pesquisa Agropecuária Brasileira, Brasília, v.30, n.11, p.1327-33, 1995. 
FAVARIN, J.L.; DOURADO NETO, D.; GARCIA Y GARCIA, A.; VILA NOVA, N.A.; FAVARIN, M. da G.G.V. Equações para a estimativa do índice de área foliar do cafeeiro. Pesquisa Agropecuária Brasileira, Brasília, v.37, n.6, p.769-73, 2002.

FAZUOLI, L.C. Cultivares IAC de café. O Agronômico, Campinas, v.51, n.1, p.27-34, 1999.

MIRANDA, E.M. de; PEREIRA, R. de C.A.; BERGO, C.L. Comportamento de seis linhagens de café (Coffea arabica L.) em condições de sombreamento e a pleno sol no estado do Acre, Brasil. Ciência e Agrotecnologia, Lavras, v.23, n.1, p.62-9, 1999.

MORALES, D. Effect of different soil moisture levels on growth and yield of coffee trees in full sunlight. Cultivos tropicales, Cuba, v.3, n.3, p.65-73, 1981.

NAZARENO, R.B. Crescimento inicial da parte aérea do cafeeiro rubi influenciado por NPKe regime hídrico. 2002. 64 f. Dissertação (Mestrado em Irrigação e Agroambiente) - Universidade de Brasília, Brasília, 2002.

PAVAN, M.A.; CHAVES, J.C.D. Influência da densidade de plantio de cafeeiros sobre a fertilidade do solo. In: SIMPÓSIO INTERNACIONAL SOBRE CAFÉ ADENSADO, 1., 1994, Londrina. Anais... Londrina: IAPAR, 1996. p.87-105.

SCALCO, M.S.; MORAIS, A.R. de; COLOMBO, A.; CARVALHO, C.H.M. de; FARIA, M.A. de; MELO, L.Q. de; SILVA, E.L. da. Influência de diferentes critérios de irrigação e densidades de plantio sobre o crescimento inicial do cafeeiro. In: SIMPÓSIO BRASILEIRO DE PESQUISA EM CAFEICULTURA IRRIGADA, 5., 2002, Araguari. Anais... Uberlândia: Universidade Federal de Uberlândia, 2002. p.150-55.

SERA, T.; ALTEIA, M.Z.; PETEK, M.R.; MATA, J.S. da. Novas cultivares para o modelo IAPAR de café adensado para o Paraná. In: CONGRESSO BRASILEIRA DE PESQUISAS CAFEEIRAS, 28., 2002, Caxambu. Trabalhos apresentados... Rio de Janeiro: MAPA/PROCAFÉ, 2002. p.432-4.

SILVA, F.A.M. da; RESCK, D.V.S.; FRANÇA-DANTAS, M.S.; FEITOZA, L.; EVANGELISTA, B.A. Necessidade de irrigação para a cultura do café (Coffea arabica L.) nos latossolos do Distrito Federal. In: SIMPÓSIO DE PESQUISA DOS CAFÉS DO BRASIL, 1., 2000, Poços de Caldas. Resumos expandidos... Brasília: Embrapa Café, 2000. v.1, p.101-3.

SILVA, J.C.P. da. Crescimento inicial da parte aérea do cafeeiro acaiá cerrado influenciado por espaçamento e regime hídrico. 2002. 67 f. Dissertação (Mestrado em Irrigação e Agroambiente) Universidade de Brasília, Brasília, 2002.

SOARES, A.R.; MANTOVANI, E.C.; SOUZA, L.O.C. de; BONOMO, R. Estudo comparativo do desenvolvimento do café Catuaí IAC 144 em condições de irrigação por gotejamento e em condições de sequeiro. Viçosa - MG: Associação dos Engenheiros Agrícolas de Minas Gerais, UFV/DEA, 2001. 118 p. (Boletim Técnico, 4). 